\title{
Resveratrol Modulates the Gut-Brain Axis: Focus on Glucagon-Like Peptide-1, 5-HT, and Gut Microbiota
}

\author{
Ji Yeon Chung ${ }^{1 \dagger}$, Jae-Ho Jeong ${ }^{2 \dagger}$ and Juhyun Song ${ }^{3 *}$ \\ ${ }^{1}$ Department of Neurology, Chosun University Medical School, Gwangju, South Korea, ${ }^{2}$ Department of Microbiology, \\ Chonnam National University Medical School, Gwangju, South Korea, ${ }^{3}$ Department of Anatomy, Chonnam National \\ University Medical School, Gwangju, South Korea
}

OPEN ACCESS

Edited by:

George Tetz,

Human Microbiology Institute

United States

Reviewed by:

Vanessa Castelli,

University of L'Aquila, Italy

Silvia Giatti,

University of Milan, Italy

*Correspondence:

Juhyun Song

juhyunsong@chonnam.ac.kr

tThese authors have contributed equally to this work

Received: 28 July 2020

Accepted: 23 October 2020

Published: 24 November 2020

Citation:

Chung JY, Jeong J-H and Song $J$

(2020) Resveratrol Modulates the

Gut-Brain Axis: Focus on

Glucagon-Like Peptide-1, 5-HT, and

Gut Microbiota.

Front. Aging Neurosci. 12:588044.

doi: 10.3389/fnagi.2020.588044
Resveratrol is a natural polyphenol that has anti-aging and anti-inflammatory properties against stress condition. It is reported that resveratrol has beneficial functions in various metabolic and central nervous system (CNS) diseases, such as obesity, diabetes, depression, and dementia. Recently, many researchers have emphasized the connection between the brain and gut, called the gut-brain axis, for treating both CNS neuropathologies and gastrointestinal diseases. Based on previous findings, resveratrol is involved in glucagon-like peptide 1 (GLP-1) secreted by intestine $L$ cells, the patterns of microbiome in the intestine, the 5-hydroxytryptamine (5-HT) level, and CNS inflammation. Here, we review recent evidences concerning the relevance and regulatory function of resveratrol in the gut-brain axis from various perspectives. Here, we highlight the necessity for further study on resveratrol's specific mechanism in the gut-brain axis. We present the potential of resveratrol as a natural therapeutic substance for treating both neuropathology and gastrointestinal dysfunction.

Keywords: resveratrol, gut-brain axis, glucagon-like peptide-1 (GLP-1), 5-hydroxytryptamine (5-HT), gut microbiota

\section{INTRODUCTION}

Resveratrol is a polyphenol that is secreted by grapes and berries (Wang et al., 2013) and could regulate insulin action, lipid metabolism, and glucose homeostasis (Chen et al., 2017). Resveratrol has been reported to have an anti-aging effect and to regulate inflammation in various organs (Buhrmann et al., 2017; Malaguarnera, 2019).

Recent researchers have highlighted the connection between the gut and brain, called the "gutbrain axis," owing to the proven linkage between many factors related with the brain and the intestine (Louwies et al., 2020; Parker C. G. et al., 2020). In addition, researchers have discussed the connection between the gut and brain as key to finding therapeutic treatments for both neurological dysfunction such as cognitive decline and impaired gastrointestinal homeostasis (Rhee et al., 2009). Many cell types associated with the enteric nervous system including enteric epithelial cells, cells of Cajal, and enterochromaffin cells are influenced by the gut-brain axis (Mayer et al., 2014b).

Numerous researchers have highlighted resveratrol as a multiple regulator in various organs including the pancreas, liver, brain, and gut (Kumar et al., 2013; Movahed et al., 2013; Caron et al., 2014). Based on previous studies, we assume that there is considerable potential for resveratrol to regulate the gut-brain axis. Here, we review the significant evidences related to resveratrol's beneficial roles in the gut and brain. 


\section{RESVERATROL}

Resveratrol, a natural polyphenol, is secreted by specific plants such as grapes and berries in response to stress conditions including infection, sunlight, and climate (Singh et al., 2015; De Sa Coutinho et al., 2018).

Resveratrol could boost glucose uptake in the absence of insulin (Zhao et al., 2019). It also exerts an anti-diabetic property via enhancing mitochondrial function and an anti-aging property via promoting energy expenditure (Ren et al., 2017; Zou et al., 2017). Resveratrol induces the expression of adiponectin (one of the adipokines) and improves insulin resistance in adipocytes and inhibits the inflammatory response (Sadruddin and Arora, 2009; Timmers et al., 2011). Resveratrol is specifically known to activate mammalian nicotinamide adenosine dinucleotidedependent deacetylase SIRT1, which is involved in regulating glucose homeostasis, lipid metabolism, and the activation of mitochondrial function (Baur, 2010; Zhou et al., 2018). SIRT1 is a NAD+-dependent protein deacetylase that is a critical regulator of energy homeostasis-dependent nutrient metabolism (Vassilopoulos et al., 2011; Aguilar-Arnal et al., 2016).

Resveratrol activates mitochondrial function and enhances insulin secretion by activating SIRT1 (Ahuja et al., 2007; Ma et al., 2017). Resveratrol could also activate SIRT2, which subsequently mimics calorie restriction and expands lifespan (Smith et al., 2009; Gambini et al., 2015).

Several other studies demonstrated that resveratrol could alleviate hyperglycemia in a diabetic mouse model and obese mouse model (Ramadori et al., 2009; Rehman et al., 2018).

In the obese mouse model, some studies demonstrated that resveratrol had improved motor dysfunction, reduced fat mass, and induced positive changes in lipid profiles (Shang et al., 2008; Rivera et al., 2009; Haley et al., 2017).

Clinically, resveratrol has been reported to improve pathologies in type 2 diabetes, cardiovascular disease, and cognitive dysfunction (Novelle et al., 2015). Moreover, resveratrol could reduce fasting blood glucose and the level of HbAlc under diabetic conditions (Bhatt et al., 2012; Movahed et al., 2013).

Mechanistically, resveratrol induces the secretion of insulin through sulfonylurea receptors mediated by the adenosine monophosphate (AMP)-activated protein kinase (AMPK) pathway (Hubbard et al., 2013) and peroxisomal proliferatoractivated receptor $\alpha(\operatorname{PPAR} \alpha)$ (Caron et al., 2014). Furthermore, resveratrol-induced SIRT1 activation attenuates inflammatory responses and pro-inflammatory cytokine secretion mainly through NF-kB- and AP-1-dependent signal pathways (Deng et al., 2008; Dao et al., 2011; Xu L. et al., 2018) (Figure 1).

In the CNS, resveratrol protects neurons which were damaged under oxidative conditions and contributed to low levels of antioxidant defense enzymes, which ultimately enhanced memory function (Kumar et al., 2013).

Similarly, another study showed that resveratrol has a neuroprotective effect via its anti-inflammatory action by regulating various neurotransmitters such as brain-derived neurotrophic factor (BDNF) and phosphodiesterases (PDEs) (Chung, 2012) (Figure 1).
Additionally, resveratrol activates the SIRT1 gene, considered an anti-aging related gene, in the duodenum and also rescues insulin resistance and improves neuronal networks in the brain (Cote et al., 2015).

Considering these findings, resveratrol has beneficial effects against stress conditions such as inflammation, oxidative stress, hyperglycemia, and dyslipidemia. Further, resveratrol influences various organs including the brain and intestine through blood and may act as a crucial mediator in the gut-brain axis.

\section{RESVERATROL AND THE GUT-BRAIN AXIS}

\section{Resveratrol Contributes to the Gut-Brain} Axis by Regulating the Expression of GLP-1 Lately, the relationship between the gut and brain has emerged as a critical issue for treatment of neuronal disorders, such as depression and dementia, as well as gastrointestinal diseases, such as diarrhea and irritable bowel syndrome (Haj Kheder et al., 2018; Simren et al., 2018, 2019).

Based on recent researches, the pathogenesis of gastrointestinal diseases is related to the connection between the neuroendocrine network and gastrointestinal function (Koloski et al., 2012; Browning and Travagli, 2014; Yarandi et al., 2016).

Glucagon-like peptide-1 (GLP-1), an incretin hormone and a major hormone of the gut-brain axis, is linked to the control of energy homeostasis and the development of obesity (Salehi and Purnell, 2019).

GLP-1 is produced from intestinal L cells and stimulates the secretion of insulin. It enhances impaired glucose and lipid metabolism and also inhibits inflammation (Liu et al., 2013; Shah et al., 2013; Mulvihill, 2018). The major role of GLP1 is to stimulate insulin secretion by inducing pancreatic beta cell proliferation (Morris, 2017). GLP-1 crosses the blood-brain barrier (BBB) and influences the brain as well as diverse organs (Hunter and Holscher, 2012).

In the brain, GLP-1 is synthesized by specific neurons within the nucleus of the solitary tract (Tauchi et al., 2008; Card et al., 2018). Subsequently, these GLP-1 producing neurons project to wide brain areas including the hypothalamus and cortex (Llewellyn-Smith et al., 2011; Ghosal et al., 2013).

One study demonstrated that central administration of GLP1 leads to marked improvement of neuronal function in several brain regions such as the paraventricular nucleus, area postrema, supraoptic nucleus, arcuate nucleus, and nucleus tractus solitarius (Tauchi et al., 2008).

Another study showed that GLP-1R agonist exendin-4 could increase $c$-fos expression on neurons in various brain regions including nucleus tractus solitarius (Sarkar et al., 2003; Baggio et al., 2008).

GLP-1 could rapidly control glucose homeostasis after food intake, because GLP-1 receptors are located in the intestine, portal vein, pancreas, and brain, and also GLP-1 induces vagal afferent neurons innervated into gut (Iwasaki et al., 2018).

One study showed that GLP-1R antagonist's administration damages glucose tolerance and aggravates insulin resistance (Vahl et al., 2007). 


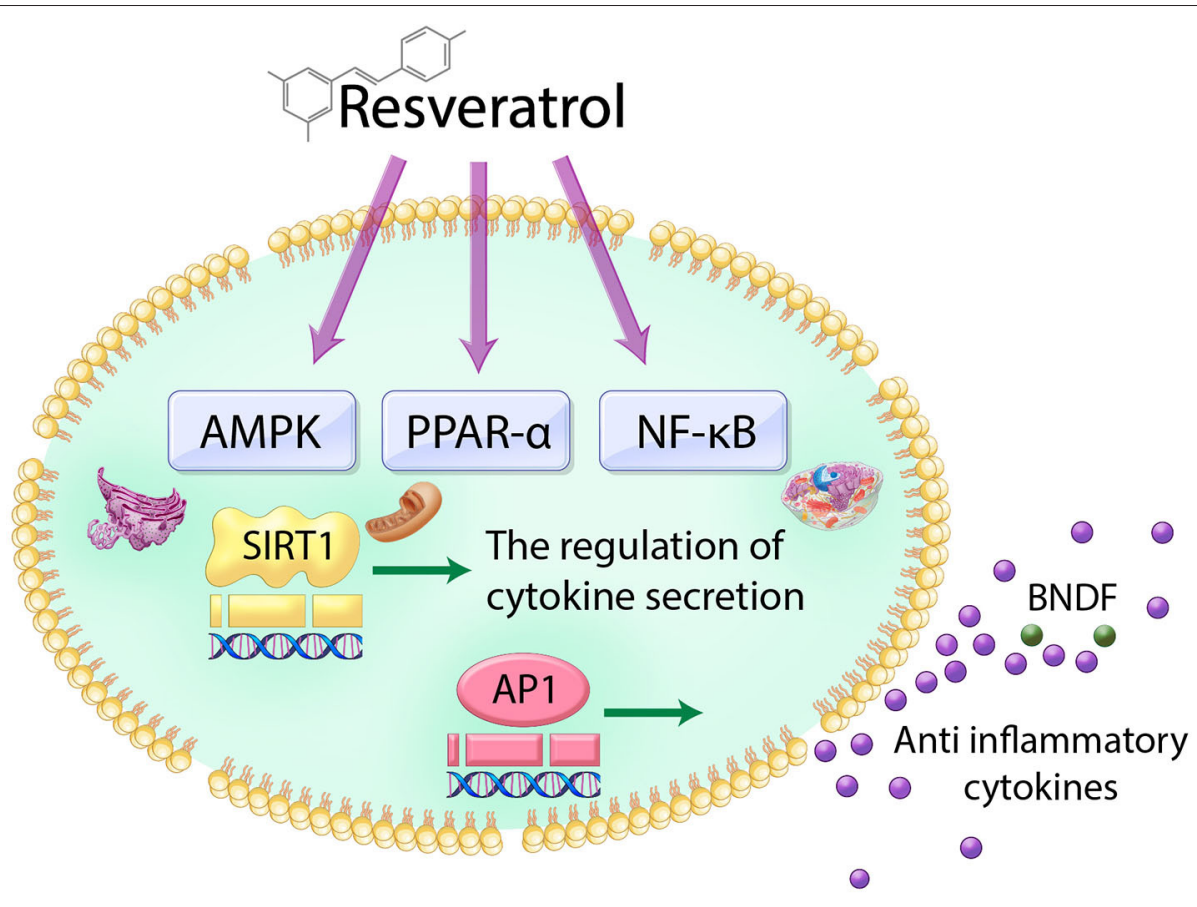

FIGURE 1 | Schematic image of the action of resveratrol in cell. Resveratrol triggers the NF-kB, AMPK, and PPAR- $\alpha$ and subsequently regulates AP-1 and SIRT1 genes. Therefore, the action of resveratrol in the cell leads to the increase of antioxidant cytokine secretion and neurotrophic factor BDNF.

In addition, another study demonstrated that the inhibition of GLP-1R in brain aggravates glucose homeostasis and insulin sensitivity (Knauf et al., 2008). Taken together, GLP-1 and GLP$1 \mathrm{R}$ agonist act as the important regulators of glucose homeostasis and insulin action both in systemic circulation and in CNS.

Some studies have suggested that GLP-1 has neuroprotective roles (Martin et al., 2009; Wang et al., 2018) in neurodegenerative diseases, such as Alzheimer's disease (Holscher, 2014), Parkinson's disease (Li et al., 2009), and stroke (Darsalia et al., 2012, 2018).

One study demonstrated that GLP-1 receptor signaling is considerably related to the connection between diabetes and the brain (Duarte et al., 2013). Other studies have reported that GLP-1 and its analogs including exendin-4 could protect neurons against oxidative stress in brain with dementia and dementia mimic in vitro cell models (An et al., 2015; Chen et al., 2016; Wang et al., 2018). Based on these findings, GLP-1 is a major gut hormone that circulates in the body and influences brain function.

One study also reported that treatment with GLP-1 receptor agonist could enhance both glycemic control and memory function (Berezin, 2016).

The positive correlation between impaired glycemic control like hyperglycemia and memory loss caused by neuronal cell damage have been proved as previous significant data (Biessels and Gispen, 2005; Carvalho et al., 2012).

Previous study mentioned that GLP-1 could be used as a controller for diabetes and ultimately GLP-1 mimic and GLP-1R agonists such as liraglutide clinically could be used for patients with diabetes in the present time (Vilsboll and Holst, 2004; Amori et al., 2007; Campbell and White, 2008; Gallwitz, 2011; Duarte et al., 2013).

Furthermore, GLP-1 may contribute to memory loss as well as improved systemic body function in diabetes by enhancing glucose tolerance and insulin resistance, suggesting that impaired glucose metabolism and poor insulin sensitivity aggravates memory loss and neuroinflammation (Rom et al., 2019).

A recent study mentioned that GLP-1R agonists improve synaptic dysfunction, strengthen long-term potentiation (LTP), and finally lead to improved cognitive function (Isacson et al., 2011).

Several studies reported that GLP-1R agonists and GLP-1 analogs could promote learning and memory function (During et al., 2003; Abbas et al., 2009), attenuate neuroinflammation against brain damage (Hattori et al., 2010), and promote neurite outgrowth, leading to stable neural connectivity (Perry et al., 2002).

One study demonstrated that GLP-1 receptor agonist exenatide could ameliorate cell stress response through SIRT1 (Xu et al., 2014).

These functions of GLP-1 receptor agonist are strongly linked to the activation of SIRT1, which could be promoted by resveratrol (Samson and Bajaj, 2013; Xu et al., 2014).

Another in vitro study reported that GLP-1 protects cellular apoptosis through the activation of SIRT1 in in vitro system (Shi and Huang, 2018).

Several studies have reported that GLP-1 and the GLP-1 receptor stimulate the activity of FoxO1 that plays a crucial 
role in cellular metabolism through SIRT-1-dependent FoxO1 deacetylation and Akt-dependent FoxO1 phosphorylation (Bastien-Dionne et al., 2011; Daitoku et al., 2011; Lee et al., 2012). Other studies demonstrated that SIRT1 activation by the GLP-1 agonist exendin-4 treatment protects mice under a high fat diet condition (Lee et al., 2012) and attenuates palmitate-induced ER stress and mitochondrial dysfunction (Lee et al., 2014). Resveratrol increases the release of GLP-1 in a high-fat-fed diabetes mouse model (Dao et al., 2011) and improves the epithelial cells of the intestine (Zhuang et al., 2019).

Another study demonstrated resveratrol does not directly affect the release of GLP-1 (Knop et al., 2013; Thazhath et al., 2016). Thus, the mechanism of resveratrol on the release of GLP1 is controversial until now; we need to investigate more directly to understand the mechanism of resveratrol about the release of GLP-1.

Based on these previous studies, we assume that resveratrol could promote the effect of GLP-1 in the intestine and CNS through the activation of diverse genes such as SIRT1 and Foxo genes. Further studies on the genetic and cellular mechanisms elicited by resveratrol via GLP-1 may be helpful to understand the correlation between resveratrol and the gut-brain axis.

\section{Resveratrol Contributes to the Gut-Brain Axis by Involving 5-HT}

Resveratrol has regulatory functions in the gut-brain axis through another hormone pathway as well as the GLP-1 pathway. Serotonin 5-hydroxytryptamine (5-HT) is expressed in both the CNS and gastrointestinal tracts, and currently 5-HT has been considered as an important target in the gut-brain axis.

5-HT is a growth factor, a paracrine factor, and an enteric neurotransmitter (Gershon and Tack, 2007), which is mainly found in the gut enterochromaffin cells. It is directly linked to depressive behavior, sleep pattern, food appetite, sexual behavior, or the control of temperature (Li et al., 2011; Yohn et al., 2017). 5-HT influences maintenance of the gastrointestinal mucosa and modulates the enteric nervous system (Gross et al., 2012).

Enterochromaffine cells in gut produce intrinsic afferent neurons of myenteric plexus in gut and are influenced by $5-\mathrm{HT}_{3}$ antagonist and $5-\mathrm{HT}_{4}$ agonist's inhibition (Bertrand et al., 2000; Bertrand and Bertrand, 2010; Hoffman et al., 2012). Previous studies mentioned that 5-HT produced from enterochromaffin cells in gut could promote sensory nerve activation and finally contribute to neuronal electrical activity evoked in CNS (Johanson, 2004; Chey and Cash, 2005).

Furthermore, 5-HT derived from gut protects gastrointestinal cells against neuroinflammation (Linden et al., 2005; Spohn et al., 2016)

A previous study demonstrated that the 5-HT neurotransmitter derived from brain promotes cyclic AMP (cAMP) synthesis through 5-HT receptors (Prasad et al., 2019). The change in cAMP signaling could affect both the neuropathology of major depressive disorder in CNS and gastrointestinal epithelial dysfunction in gut (Reierson et al., 2011; Cheung et al., 2019). Thus, the regulation of cAMP signaling by 5 -HT should be studied further because cAMP signaling in gut and in brain contributes to various neuronal functions. Moreover, an impaired 5-HT system in gut triggers irritable bowel syndrome, and the gastrointestinal motility is increased (Grenham et al., 2011). In addition, the receptors of 5-HT have been reported to be directly involved in depression (Celada et al., 2004), anxiety, and stress-induced dyspeptic ulcers (O’mahony et al., 2006).

Considering previous data, 5-HT derived from gut and brain contributes to nervous systems globally, and the circulation of 5-HT in the body mediates the gut-brain axis (Yano et al., 2015).

A current study proved that resveratrol regulates the gut-brain axis by controlling the 5-HT-dependent pathway in an irritable bowel syndrome rat model and specifically that resveratrol influences various organs including brain hippocampus, ileum, and colon through 5-HT axis (Yu et al., 2019). One recent study highlighted that resveratrol contributes to many pathological responses through $5-\mathrm{HT}_{2 \mathrm{C}}$ receptordependent signaling (Peng et al., 2018).

Another recent study demonstrated that resveratrol could increase the expression of 5-HT, leading to the improvement of brain function (Nabavi et al., 2017). Furthermore, the neuroprotective function of resveratrol in the depressive brain hippocampus was proved to be exerted via 5-HT (Xu et al., 2010). Most of the released 5-HT is stored in enteroendocrine cells in the intestine, and therefore gut homeostasis is important to maintain the 5-HT level in the body (Enck et al., 2016).

Several studies have mentioned the neurological role of resveratrol in depression and anxiety (Yu et al., 2013; Li et al., 2017) and the gut homeostasis-related role of resveratrol in stress-induced irritable bowel syndrome (Xu Y. et al., 2018).

One current study reported that the inhibition of $5-\mathrm{HT}$ release attenuates the activation of GLP-1 receptor signaling and highlighted the relationship between GLP-1 and 5-HT serotonin system (Anderberg et al., 2017).

Another study mentioned that GLP-1 receptor agonist liraglutide could reduce the expression of 5-HT2A receptor and subsequently reduces body weight and inhibits serotonin synthesis in mice model (Nonogaki and Kaji, 2018).

TABLE 1 | The relationship between resveratrol and gut-brain axis.

Relevance between References
resveratrol and

gut-brain axis

Resveratrol and gut-brain axis

Resveratrol and GLP-1 Bastien-Dionne et al., 2011; Daitoku et al., 2011; Dao et al., 2011; Lee et al., 2012, 2014; Samson and Bajaj, 2013; Xu et al., 2014; Shi and Huang, 2018; Zhuang et al., 2019

Resveratrol and 5-HT Xu et al., 2010; Yu et al., 2013, 2019; Enck et al., 2016; Li et al., 2017; Nabavi et al., 2017; Peng et al., 2018; Xu L. et al., 2018

Resveratrol and gut microbiota Dao et al., 2011; Wu et al., 2011; Amri et al., 2012; Rotches-Ribalta et al., 2012; Bode et al., 2013; Qiao et al., 2014; Hsieh et al., 2015; Basholli-Salihu et al., 2016; Ling et al., 2016; Bird et al., 2017; Carrera-Quintanar et al., 2018; Hu et al., 2019 
Ripken et al. suggested that serotonin treatment could boost GLP-1 release, and the blocking of 5-HT receptor could affect the production of GLP-1 (Ripken et al., 2016).

A recent study proved that 5-HT enterochrnomaffin cells in gut regulates gut microbial metabolism and homeostasis and is affected by the activation of GLP-1 (Lund et al., 2018).

Further, ghrelin, known as a hormone for regulation of motivation and reward system among brain function, has been interacted with GLP-1 and the monoamine transmitter 5-HT (Currie et al., 2010; Abtahi et al., 2019).

GLP-1 derived from brain mainly is produced by the nucleus tractus solitarius in brain (Alhadeff et al., 2012). GLP-1 receptors are expressed in various brain areas including the hypothalamus, and GLP-1 projects to neurons in the ventral tegmental area, nucleus accumbens, and 5-HT-producing neurons in the dorsal raphe (Anderberg et al., 2017). Based on previous studies, the activation of GLP-1 leads to the release of 5-HT in brain, which is related with neurological behavior pattern.

Given previous evidences, resveratrol can control 5-HT and its receptor and also modulate release of 5-HT through GLP-1 regulation. Ultimately, resveratrol could control the neuropathology of neurological diseases such as depression and stress-induced anxiety. Also, resveratrol can regulate gut dysfunction in irritable bowel syndrome via 5-HT. Thus, we emphasize the necessity for further study of the specific mechanism and cellular pathways regulated by resveratrol and mediated by $5-\mathrm{HT}$ to fully understand the gut-brain axis.

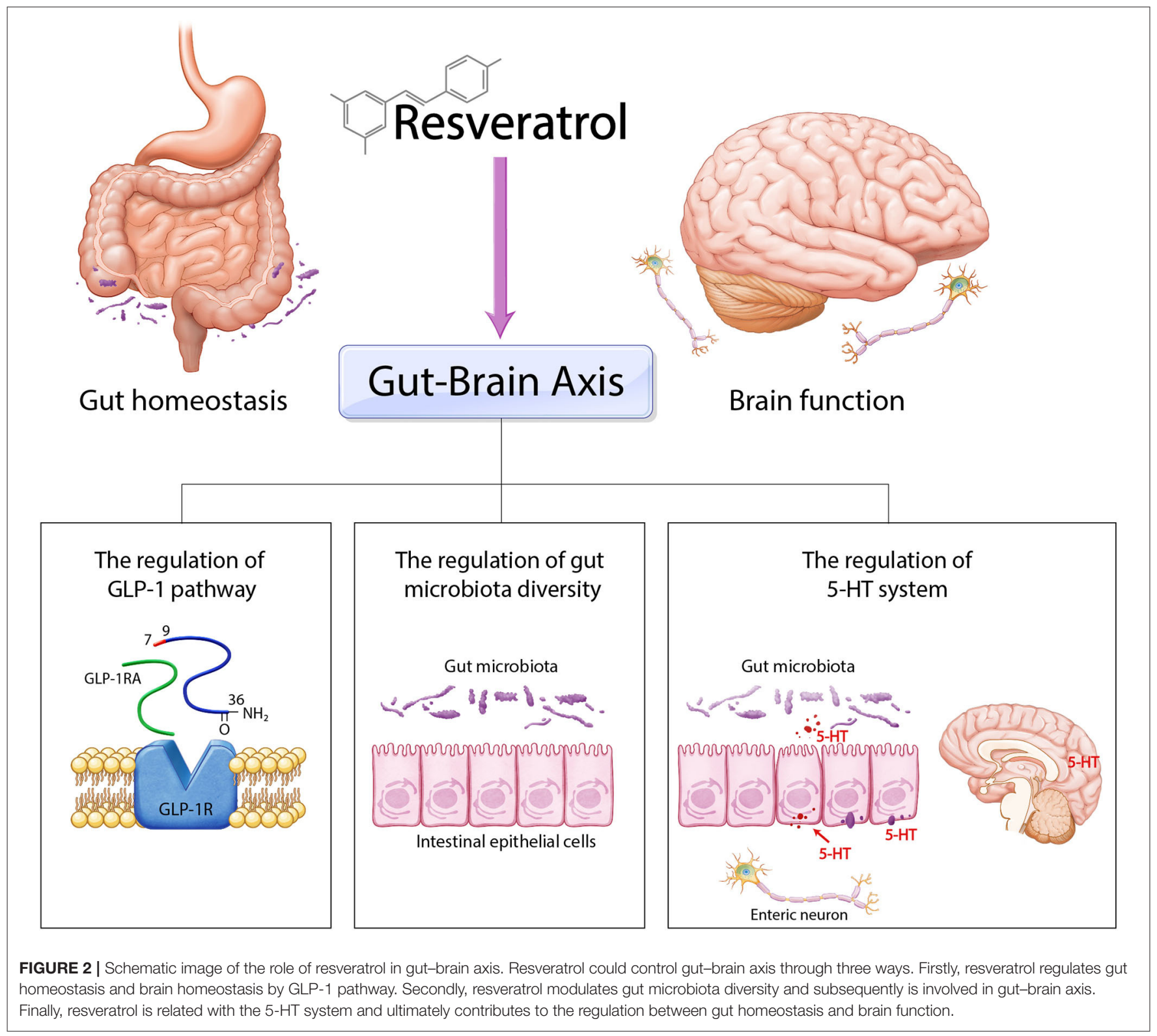




\section{Resveratrol Modulates the Gut-Brain Axis by Involving Gut Microbiota}

Resveratrol is involved in the gut-brain axis through another mode in addition to the GLP-1 pathway and 5-HT system.

Recently, gut microbiota is emerging as an important node in the gut-brain axis (Louwies et al., 2020). A previous study suggested that there is an interaction between intestinal microbes and the brain and proved that intestinal microbes could dramatically enhance encephalopathy (Parker A. et al., 2020). Significant data from other studies support the function of microbiota in neurological disorders such as anxiety, autism, and depression (Mayer et al., 2014a; Sharon et al., 2019; Sun et al., 2019; Du et al., 2020).

Resveratrol administration could be metabolized by the liver, intestinal tract, and gut microbiota (Walle, 2011). A recent study demonstrated that gut microbiota contributes to metabolization of resveratrol precursors to resveratrol and also could increase resveratrol's bioavailability (Rotches-Ribalta et al., 2012; BasholliSalihu et al., 2016). Dihydroresveratrol, 3,4'-dihydroxybibenzyl, and 3,4'-dihydroxy-trans-stilbene have been reported to be the major microbiota-derived metabolites made from resveratrol (Juan et al., 2010; Bird et al., 2017; Brandt et al., 2018).

Specifically, dihydroresveratrol as a metabolite of resveratrol is produced in the intestines such as the cecum, colon, and rectum through fermentation by the gut microbiota (Amri et al., 2012; Hu et al., 2019). Moreover, resveratrol was also glycosylated in the intestine to produce piceid (Rotches-Ribalta et al., 2012). Given that resveratrol was metabolized by gut microbiota (Bode et al., 2013; Carrera-Quintanar et al., 2018), resveratrol could influence the composition and diversity of gut bacteria (Carrera-Quintanar et al., 2018). Likewise, resveratrol and gut microbiota could influence each other. Specifically, Bifidobacteria infantis and Lactobacillus acidophilus are strongly linked to piceid production from resveratrol (Basholli-Salihu et al., 2016). Interestingly, a study demonstrated that resveratrol promotes gut microbiota diversity by suppressing the growth of Enterococcus faecalis and increasing the Lactobacillus and Bifidobacterium populations (Qiao et al., 2014).

Recently, resveratrol has been reported to improve gut microbiota in bowel diseases under harsh oxidative stress $(\mathrm{Hu}$ et al., 2019). One study suggested that resveratrol attenuated inflammation and improved effects of GLP-1 such as the secretion of insulin and ultimately induced a prebiotic effect to control gut microbiota in a diabetic mouse model (Dao et al., 2011).

A clinical study has reported that resveratrol treatment exerts cardiovascular and anti-obesity effects by ameliorating gut microbiota diversity (Bird et al., 2017). Resveratrol enhances the improvement of gut permeability and the integrity of intestinal tight junction proteins by controlling gut microbiota diversity (Hsieh et al., 2015; Ling et al., 2016). It has also been reported that resveratrol influences the glucuronidation and sulfation reactions in the duodenum (Wu et al., 2011).

These previous findings demonstrate that resveratrol and gut microbiota influence each other. Furthermore, resveratrol could enhance the gut microbiota diversity and the gut barrier's homeostasis. These effects of resveratrol should be investigated further to determine the specific gut bacteria that affect the gut-brain axis.

\section{CONCLUSIONS}

Here, we reviewed previous significant evidence of the effect of resveratrol on the gut-brain axis (Table 1). We summarized three regulatory nodes of resveratrol in the gut-brain axis including the regulation of GLP-1, the involvement of the 5-HT system, and the control of gut microbiota diversity (Figure 2). Resveratrol modulates various cellular responses such as lipid droplet accumulation and insulin resistance and regulates diverse cellular signalings including AMPK, cAMP, and NF- $\mathrm{B}$ signaling and also controls the balance of neurotransmitters such as BDNF and 5-HT, involved in both the progression of neuropathology and gut homeostasis. Hence, we emphasize the necessity for further experimental study about the specific mechanism of resveratrol in gut and brain. Taken together, we suggest that the application of resveratrol as a natural polyphenol for treatment of both neurological disorders and intestinal dysfunction may be a safe and effective therapeutic solution for CNS and intestinal diseases simultaneously.

\section{AUTHOR CONTRIBUTIONS}

JC, J-HJ, and JS contributed to the writing of the text. JC and J-HJ made and revised all figures. JS wrote and finalized the revised manuscript. All authors contributed to the article and approved the submitted version.

\section{FUNDING}

This research was supported by Basic Science Research Program through the National Research Foundation of Korea (NRF) funded by the Ministry of Education [Grant Numbers: NRF-2019R1F1A1054111 (JS) and NRF-2017R1A6A3A04006167 (J-HJ)].

\section{REFERENCES}

Abbas, T., Faivre, E., and Holscher, C. (2009). Impairment of synaptic plasticity and memory formation in GLP- 1 receptor KO mice: interaction between type 2 diabetes and Alzheimer's disease. Behav. Brain Res. 205, 265-271. doi: 10.1016/j.bbr.2009.06.035

Abtahi, S., Howell, E., Salvucci, J. T., Bastacky, J. M. R., Dunn, D. P., and Currie, P. J. (2019). Exendin-4 antagonizes the metabolic action of acylated ghrelinergic

signaling in the hypothalamic paraventricular nucleus. Gen. Comp. Endocrinol. 270, 75-81. doi: 10.1016/j.ygcen.2018.10.008

Aguilar-Arnal, L., Ranjit, S., Stringari, C., Orozco-Solis, R., Gratton, E., and Sassone-Corsi, P. (2016). Spatial dynamics of SIRT1 and the subnuclear distribution of NADH species. Proc. Natl. Acad. Sci. U.S.A. 113, 12715-12720. doi: $10.1073 /$ pnas. 1609227113

Ahuja, N., Schwer, B., Carobbio, S., Waltregny, D., North, B. J., Castronovo, V., et al. (2007). Regulation of insulin secretion by SIRT4, a 
mitochondrial ADP-ribosyltransferase. J. Biol. Chem. 282, 33583-33592. doi: 10.1074/jbc.M705488200

Alhadeff, A. L., Rupprecht, L. E., and Hayes, M. R. (2012). GLP-1 neurons in the nucleus of the solitary tract project directly to the ventral tegmental area and nucleus accumbens to control for food intake. Endocrinology 153, 647-658. doi: 10.1210/en.2011-1443

Amori, R. E., Lau, J., and Pittas, A. G. (2007). Efficacy and safety of incretin therapy in type 2 diabetes: systematic review and meta-analysis. JAMA 298, 194-206. doi: 10.1001/jama.298.2.194

Amri, A., Chaumeil, J. C., Sfar, S., and Charrueau, C. (2012). Administration of resveratrol: what formulation solutions to bioavailability limitations? J. Control. Release 158, 182-193. doi: 10.1016/j.jconrel.2011.09.083

An, F. M., Chen, S., Xu, Z., Yin, L., Wang, Y., Liu, A. R., et al. (2015). Glucagon-like peptide-1 regulates mitochondrial biogenesis and tau phosphorylation against advanced glycation end product-induced neuronal insult: studies in vivo and in vitro. Neuroscience 300, 75-84. doi: 10.1016/j.neuroscience.2015.05.023

Anderberg, R. H., Richard, J. E., Eerola, K., Lopez-Ferreras, L., Banke, E., Hansson, C., et al. (2017). Glucagon-like peptide 1 and its analogs act in the dorsal raphe and modulate central serotonin to reduce appetite and body weight. Diabetes 66, 1062-1073. doi: 10.2337/db16-0755

Baggio, L. L., Huang, Q., Cao, X., and Drucker, D. J. (2008). An albuminexendin-4 conjugate engages central and peripheral circuits regulating murine energy and glucose homeostasis. Gastroenterology 134, 1137-1147. doi: 10.1053/j.gastro.2008.01.017

Basholli-Salihu, M., Schuster, R., Mulla, D., Praznik, W., Viernstein, H., and Mueller, M. (2016). Bioconversion of piceid to resveratrol by selected probiotic cell extracts. Bioprocess Biosyst. Eng. 39, 1879-1885. doi: 10.1007/s00449-016-1662-1

Bastien-Dionne, P. O., Valenti, L., Kon, N., Gu, W., and Buteau, J. (2011), Glucagon-like peptide 1 inhibits the sirtuin deacetylase SirT1 to stimulate pancreatic beta-cell mass expansion. Diabetes 60, 3217-3222. doi: $10.2337 / \mathrm{db} 11-0101$

Baur, J. A. (2010). Resveratrol, sirtuins, and the promise of a DR mimetic. Mech. Ageing Dev. 131, 261-269. doi: 10.1016/j.mad.2010.02.007

Berezin, A. (2016). Metabolic memory phenomenon in diabetes mellitus: achieving and perspectives. Diabetes Metab. Syndr. 10, S176-183. doi: 10.1016/j.dsx.2016.03.016

Bertrand, P. P., and Bertrand, R. L. (2010). Serotonin release and uptake in the gastrointestinal tract. Auton. Neurosci. 153, 47-57. doi: 10.1016/j.autneu.2009.08.002

Bertrand, P. P., Kunze, W. A., Furness, J. B., and Bornstein, J. C. (2000). The terminals of myenteric intrinsic primary afferent neurons of the guinea-pig ileum are excited by 5-hydroxytryptamine acting at 5-hydroxytryptamine- 3 receptors. Neuroscience 101, 459-469. doi: 10.1016/S0306-4522(00)00363-8

Bhatt, J. K., Thomas, S., and Nanjan, M. J. (2012). Resveratrol supplementation improves glycemic control in type 2 diabetes mellitus. Nutr. Res. 32, 537-541. doi: $10.1016 /$ j.nutres.2012.06.003

Biessels, G. J., and Gispen, W. H. (2005). The impact of diabetes on cognition: what can be learned from rodent models? Neurobiol. Aging 26(Suppl. 1), 36-41. doi: 10.1016/j.neurobiolaging.2005.08.015

Bird, J. K., Raederstorff, D., Weber, P., and Steinert, R. E. (2017). Cardiovascular and antiobesity effects of resveratrol mediated through the gut microbiota. $A d v$. Nutr. 8, 839-849. doi: 10.3945/an.117.016568

Bode, L. M., Bunzel, D., Huch, M., Cho, G. S., Ruhland, D., Bunzel, M., et al. (2013). In vivo and in vitro metabolism of trans-resveratrol by human gut microbiota. Am. J. Clin. Nutr. 97, 295-309. doi: 10.3945/ajcn.112.049379

Brandt, N., Kotowska, D., Kristensen, C. M., Olesen, J., Lutzhoft, D. O., Halling, J. F., et al. (2018). The impact of exercise training and resveratrol supplementation on gut microbiota composition in high-fat diet fed mice. Physiol. Rep. 6:e13881. doi: 10.14814/phy2.13881

Browning, K. N., and Travagli, R. A. (2014). Central nervous system control of gastrointestinal motility and secretion and modulation of gastrointestinal functions. Compr. Physiol. 4, 1339-1368. doi: 10.1002/cphy. c130055

Buhrmann, C., Popper, B., Aggarwal, B. B., and Shakibaei, M. (2017). Resveratrol downregulates inflammatory pathway activated by lymphotoxin alpha (TNFbeta) in articular chondrocytes: comparison with TNF-alpha. PLOS ONE 12:e0186993. doi: 10.1371/journal.pone.0186993
Campbell, R. K., and White, J. R. Jr. (2008). More choices than ever before: emerging therapies for type 2 diabetes. Diabetes Educ. 34, 518-534. doi: $10.1177 / 0145721708317870$

Card, J. P., Johnson, A. L., Llewellyn-Smith, I. J., Zheng, H., Anand, R., Brierley, D. I., et al. (2018). GLP-1 neurons form a local synaptic circuit within the rodent nucleus of the solitary tract. J. Comp. Neurol. 526, 2149-2164. doi: $10.1002 / \mathrm{cne} .24482$

Caron, A. Z., He, X., Mottawea, W., Seifert, E. L., Jardine, K., Dewar-Darch, D., et al. (2014). The SIRT1 deacetylase protects mice against the symptoms of metabolic syndrome. FASEB J. 28, 1306-1316. doi: 10.1096/fj.13-243568

Carrera-Quintanar, L., Lopez Roa, R. I., Quintero-Fabian, S., Sanchez-Sanchez, M. A., Vizmanos, B., and Ortuno-Sahagun, D. (2018). Phytochemicals that influence gut microbiota as prophylactics and for the treatment of obesity and inflammatory diseases. Mediators Inflamm. 2018:9734845. doi: 10.1155/2018/9734845

Carvalho, C., Cardoso, S., Correia, S. C., Santos, R. X., Santos, M. S., Baldeiras, I., et al. (2012). Metabolic alterations induced by sucrose intake and Alzheimer's disease promote similar brain mitochondrial abnormalities. Diabetes 61, 1234-1242. doi: 10.2337/db11-1186

Celada, P., Puig, M., Amargos-Bosch, M., Adell, A., and Artigas, F. (2004). The therapeutic role of 5-HT1A and 5-HT2A receptors in depression. J. Psychiatry Neurosci. 29, 252-265.

Chen, S., Yin, L., Xu, Z., An, F. M., Liu, A. R., Wang, Y., et al. (2016). Inhibiting receptor for advanced glycation end product (AGE) and oxidative stress involved in the protective effect mediated by glucagon-like peptide-1 receptor on AGE induced neuronal apoptosis. Neurosci. Lett. 612, 193-198. doi: 10.1016/j.neulet.2015.12.007

Chen, T. Y., Ferruzzi, M. G., Wu, Q. L., Simon, J. E., Talcott, S. T., Wang, J., et al. (2017). Influence of diabetes on plasma pharmacokinetics and brain bioavailability of grape polyphenols and their phase II metabolites in the Zucker diabetic fatty rat. Mol. Nutr. Food Res. 61:10. doi: 10.1002/mnfr.201700111

Cheung, S. G., Goldenthal, A. R., Uhlemann, A. C., Mann, J. J., Miller, J. M., and Sublette, M. E. (2019). Systematic review of gut microbiota and major depression. Front. Psychiatry 10:34. doi: 10.3389/fpsyt.2019.00034

Chey, W. D., and Cash, B. D. (2005). Cilansetron: a new serotonergic agent for the irritable bowel syndrome with diarrhoea. Expert Opin. Investig. Drugs 14, 185-193. doi: 10.1517/13543784.14.2.185

Chung, J. H. (2012). Metabolic benefits of inhibiting cAMP-PDEs with resveratrol. Adipocyte 1, 256-258. doi: 10.4161/adip.21158

Cote, C. D., Rasmussen, B. A., Duca, F. A., Zadeh-Tahmasebi, M., Baur, J. A., Daljeet, M., et al. (2015). Resveratrol activates duodenal Sirtl to reverse insulin resistance in rats through a neuronal network. Nat. Med. 21, 498-505. doi: $10.1038 / \mathrm{nm} .3821$

Currie, P. J., John, C. S., Nicholson, M. L., Chapman, C. D., and Loera, K. E. (2010). Hypothalamic paraventricular 5-hydroxytryptamine inhibits the effects of ghrelin on eating and energy substrate utilization. Pharmacol. Biochem. Behav. 97, 152-155. doi: 10.1016/j.pbb.2010.05.027

Daitoku, H., Sakamaki, J., and Fukamizu, A. (2011). Regulation of FoxO transcription factors by acetylation and protein-protein interactions. Biochim. Biophys. Acta 1813, 1954-1960. doi: 10.1016/j.bbamcr.2011.03.001

Dao, T. M., Waget, A., Klopp, P., Serino, M., Vachoux, C., Pechere, L., et al. (2011). Resveratrol increases glucose induced GLP-1 secretion in mice: a mechanism which contributes to the glycemic control. PLoS ONE 6:e20700. doi: 10.1371/journal.pone.0020700

Darsalia, V., Klein, T., Nystrom, T., and Patrone, C. (2018). Glucagon-like receptor 1 agonists and DPP-4 inhibitors: anti-diabetic drugs with anti-stroke potential. Neuropharmacology 136, 280-286. doi: 10.1016/j.neuropharm.2017.08.022

Darsalia, V., Mansouri, S., Ortsater, H., Olverling, A., Nozadze, N., Kappe, C., et al. (2012). Glucagon-like peptide-1 receptor activation reduces ischaemic brain damage following stroke in Type 2 diabetic rats. Clin. Sci. 122, 473-483. doi: $10.1042 / C S 20110374$

De Sa Coutinho, D., Pacheco, M. T., Frozza, R. L., and Bernardi, A. (2018). Anti-inflammatory effects of resveratrol: mechanistic insights. Int. J. Mol. Sci. 19:1812. doi: 10.3390/ijms19061812

Deng, J. Y., Hsieh, P. S., Huang, J. P., Lu, L. S., and Hung, L. M. (2008). Activation of estrogen receptor is crucial for resveratrol-stimulating muscular glucose uptake via both insulin-dependent and -independent pathways. Diabetes 57, 1814-1823. doi: 10.2337/db07-1750 
Du, Y., Gao, X. R., Peng, L., and Ge, J. F. (2020). Crosstalk between the microbiota-gut-brain axis and depression. Heliyon 6:e04097. doi: 10.1016/j.heliyon.2020.e04097

Duarte, A. I., Candeias, E., Correia, S. C., Santos, R. X., Carvalho, C., Cardoso, S., et al. (2013). Crosstalk between diabetes and brain: glucagon-like peptide-1 mimetics as a promising therapy against neurodegeneration. Biochim. Biophys. Acta 1832, 527-541. doi: 10.1016/j.bbadis.2013.01.008

During, M. J., Cao, L., Zuzga, D. S., Francis, J. S., Fitzsimons, H. L., Jiao, X., et al. (2003). Glucagon-like peptide-1 receptor is involved in learning and neuroprotection. Nat. Med. 9, 1173-1179. doi: 10.1038/nm919

Enck, P., Aziz, Q., Barbara, G., Farmer, A. D., Fukudo, S., Mayer, E. A., et al. (2016). Irritable bowel syndrome. Nat. Rev. Dis. Primers 2:16014. doi: 10.1038/nrdp.2016.14

Gallwitz, B. (2011). Glucagon-like peptide-1 analogues for Type 2 diabetes mellitus: current and emerging agents. Drugs 71, 1675-1688. doi: 10.2165/11592810-000000000-00000

Gambini, J., Ingles, M., Olaso, G., Lopez-Grueso, R., Bonet-Costa, V., GimenoMallench, L., et al. (2015). Properties of resveratrol: in vitro and in vivo studies about metabolism, bioavailability, and biological effects in animal models and humans. Oxid. Med. Cell. Longev. 2015:837042. doi: 10.1155/2015/837042

Gershon, M. D., and Tack, J. (2007). The serotonin signaling system: from basic understanding to drug development for functional GI disorders. Gastroenterology 132, 397-414. doi: 10.1053/j.gastro.2006.11.002

Ghosal, S., Myers, B., and Herman, J. P. (2013). Role of central glucagonlike peptide-1 in stress regulation. Physiol. Behav. 122, 201-207. doi: 10.1016/j.physbeh.2013.04.003

Grenham, S., Clarke, G., Cryan, J. F., and Dinan, T. G. (2011). Braingut-microbe communication in health and disease. Front. Physiol. 2:94. doi: 10.3389/fphys.2011.00094

Gross, E. R., Gershon, M. D., Margolis, K. G., Gertsberg, Z. V., Li, Z., and Cowles, R. A. (2012). Neuronal serotonin regulates growth of the intestinal mucosa in mice. Gastroenterology 143, 408-417.e402. doi: 10.1053/j.gastro.2012.05.007

Haj Kheder, S., Heller, J., Bar, J. K., Wutzler, A., Menge, B. A., and Juckel, G. (2018). Autonomic dysfunction of gastric motility in major depression. J. Affect. Disord. 226, 196-202. doi: 10.1016/j.jad.2017.09.049

Haley, M. J., Mullard, G., Hollywood, K. A., Cooper, G. J., Dunn, W. B., and Lawrence, C. B. (2017). Adipose tissue and metabolic and inflammatory responses to stroke are altered in obese mice. Dis. Model. Mech. 10, 1229-1243. doi: $10.1242 / \mathrm{dmm} .030411$

Hattori, Y., Jojima, T., Tomizawa, A., Satoh, H., Hattori, S., Kasai, K., et al. (2010). A glucagon-like peptide-1 (GLP-1) analogue, liraglutide, upregulates nitric oxide production and exerts anti-inflammatory action in endothelial cells. Diabetologia 53, 2256-2263. doi: 10.1007/s00125-010-1831-8

Hoffman, J. M., Tyler, K., Maceachern, S. J., Balemba, O. B., Johnson, A. C., Brooks, E. M., et al. (2012). Activation of colonic mucosal 5-HT(4) receptors accelerates propulsive motility and inhibits visceral hypersensitivity. Gastroenterology 142, 844-854.e844. doi: 10.1053/j.gastro.2011.12.041

Holscher, C. (2014). The incretin hormones glucagonlike peptide 1 and glucose-dependent insulinotropic polypeptide are neuroprotective in mouse models of Alzheimer's disease. Alzheimers. Dement. 10, S47-54. doi: 10.1016/j.jalz.2013.12.009

Hsieh, C. Y., Osaka, T., Moriyama, E., Date, Y., Kikuchi, J., and Tsuneda, S. (2015). Strengthening of the intestinal epithelial tight junction by Bifidobacterium bifidum. Physiol Rep. 3:e12327. doi: 10.14814/phy2.12327

Hu, Y., Chen, D., Zheng, P., Yu, J., He, J., Mao, X., et al. (2019). The bidirectional interactions between resveratrol and gut microbiota: an insight into oxidative stress and inflammatory bowel disease therapy. Biomed. Res. Int. 2019:5403761. doi: $10.1155 / 2019 / 5403761$

Hubbard, B. P., Gomes, A. P., Dai, H., Li, J., Case, A. W., Considine, T., et al. (2013). Evidence for a common mechanism of SIRT1 regulation by allosteric activators. Science 339, 1216-1219. doi: 10.1126/science.1231097

Hunter, K., and Holscher, C. (2012). Drugs developed to treat diabetes, liraglutide and lixisenatide, cross the blood brain barrier and enhance neurogenesis. BMC Neurosci. 13:33. doi: 10.1186/1471-2202-13-33

Isacson, R., Nielsen, E., Dannaeus, K., Bertilsson, G., Patrone, C., Zachrisson, O., et al. (2011). The glucagon-like peptide 1 receptor agonist exendin-4 improves reference memory performance and decreases immobility in the forced swim test. Eur. J. Pharmacol. 650, 249-255. doi: 10.1016/j.ejphar.2010.10.008
Iwasaki, Y., Sendo, M., Dezaki, K., Hira, T., Sato, T., Nakata, M., et al. (2018). GLP-1 release and vagal afferent activation mediate the beneficial metabolic and chronotherapeutic effects of D-allulose. Nat. Commun. 9:113. doi: 10.1038/s41467-017-02488-y

Johanson, J. F. (2004). Options for patients with irritable bowel syndrome: contrasting traditional and novel serotonergic therapies. Neurogastroenterol. Motil. 16, 701-711. doi: 10.1111/j.1365-2982.2004.00550.x

Juan, M. E., Alfaras, I., and Planas, J. M. (2010). Determination of dihydroresveratrol in rat plasma by HPLC. J. Agric. Food Chem. 58, 7472-7475. doi: $10.1021 /$ jf100836j

Knauf, C., Cani, P. D., Kim, D. H., Iglesias, M. A., Chabo, C., Waget, A., et al. (2008). Role of central nervous system glucagon-like peptide-1 receptors in enteric glucose sensing. Diabetes 57, 2603-2612. doi: 10.2337/db07-1788

Knop, F. K., Konings, E., Timmers, S., Schrauwen, P., Holst, J. J., and Blaak, E. E. (2013). Thirty days of resveratrol supplementation does not affect postprandial incretin hormone responses, but suppresses postprandial glucagon in obese subjects. Diabet. Med. 30, 1214-1218. doi: 10.1111/dme.12231

Koloski, N. A., Jones, M., Kalantar, J., Weltman, M., Zaguirre, J., and Talley, N. J. (2012). The brain-gut pathway in functional gastrointestinal disorders is bidirectional: a 12-year prospective population-based study. Gut 61, 1284-1290. doi: 10.1136/gutjnl-2011-300474

Kumar, A., Negi, G., and Sharma, S. S. (2013). Neuroprotection by resveratrol in diabetic neuropathy: concepts and mechanisms. Curr. Med. Chem. 20, 4640-4645. doi: 10.2174/09298673113209990151

Lee, J., Hong, S. W., Chae, S. W., Kim, D. H., Choi, J. H., Bae, J. C., et al. (2012). Exendin-4 improves steatohepatitis by increasing Sirt1 expression in high-fat diet-induced obese C57BL/6J mice. PLoS ONE 7:e31394. doi: 10.1371/journal.pone.0031394

Lee, J., Hong, S. W., Park, S. E., Rhee, E. J., Park, C. Y., Oh, K. W., et al. (2014). Exendin-4 attenuates endoplasmic reticulum stress through a SIRT1-dependent mechanism. Cell Stress Chaperones 19, 649-656. doi: 10.1007/s12192-013-0490-3

Li, Y., Perry, T., Kindy, M. S., Harvey, B. K., Tweedie, D., Holloway, H. W., et al. (2009). GLP-1 receptor stimulation preserves primary cortical and dopaminergic neurons in cellular and rodent models of stroke and Parkinsonism. Proc. Natl. Acad. Sci. U.S.A. 106, 1285-1290. doi: 10.1073/pnas.0806720106

Li, Y., Yu, L., Zhao, L., Zeng, F., and Liu, Q. S. (2017). Resveratrol modulates cocaine-induced inhibitory synaptic plasticity in VTA dopamine neurons by inhibiting phosphodiesterases (PDEs). Sci. Rep. 7:15657. doi: 10.1038/s41598-017-16034-9

Li, Z., Chalazonitis, A., Huang, Y. Y., Mann, J. J., Margolis, K. G., Yang, Q. M., et al. (2011). Essential roles of enteric neuronal serotonin in gastrointestinal motility and the development/survival of enteric dopaminergic neurons. J. Neurosci. 31, 8998-9009. doi: 10.1523/JNEUROSCI.6684-10.2011

Linden, D. R., Couvrette, J. M., Ciolino, A., Mcquoid, C., Blaszyk, H., Sharkey, K. A., et al. (2005). Indiscriminate loss of myenteric neurones in the TNBSinflamed guinea-pig distal colon. Neurogastroenterol. Motil. 17, 751-760. doi: 10.1111/j.1365-2982.2005.00703.x

Ling, K. H., Wan, M. L., El-Nezami, H., and Wang, M. (2016). Protective capacity of resveratrol, a natural polyphenolic compound, against deoxynivalenolinduced intestinal barrier dysfunction and bacterial translocation. Chem. Res. Toxicol. 29, 823-833. doi: 10.1021/acs.chemrestox.6b00001

Liu, B. C., Song, X., Lu, X. Y., Li, D. T., Eaton, D. C., Shen, B. Z., et al. (2013). High glucose induces podocyte apoptosis by stimulating TRPC6 via elevation of reactive oxygen species. Biochim. Biophys. Acta 1833, 1434-1442. doi: 10.1016/j.bbamcr.2013.02.031

Llewellyn-Smith, I. J., Reimann, F., Gribble, F. M., and Trapp, S. (2011). Preproglucagon neurons project widely to autonomic control areas in the mouse brain. Neuroscience 180, 111-121. doi: 10.1016/j.neuroscience.2011.02.023

Louwies, T., Johnson, A. C., Orock, A., Yuan, T., and Greenwood-Van Meerveld, B. (2020). The microbiota-gut-brain axis: an emerging role for the epigenome. Exp. Biol. Med. 245, 138-145. doi: 10.1177/1535370219891690

Lund, M. L., Egerod, K. L., Engelstoft, M. S., Dmytriyeva, O., Theodorsson, E., Patel, B. A., et al. (2018). Enterochromaffin 5-HT cells-a major target for GLP-1 and gut microbial metabolites. Mol. Metab. 11, 70-83. doi: 10.1016/j.molmet.2018.03.004 
Ma, S., Feng, J., Zhang, R., Chen, J., Han, D., Li, X., et al. (2017). SIRT1 activation by resveratrol alleviates cardiac dysfunction via mitochondrial regulation in diabetic cardiomyopathy mice. Oxid. Med. Cell. Longev. 2017:4602715. doi: $10.1155 / 2017 / 4602715$

Malaguarnera, L. (2019). Influence of resveratrol on the immune response. Nutrients 11:946. doi: 10.3390/nu11050946

Martin, B., Golden, E., Carlson, O. D., Pistell, P., Zhou, J., Kim, W., et al. (2009). Exendin-4 improves glycemic control, ameliorates brain and pancreatic pathologies, and extends survival in a mouse model of huntington's disease. Diabetes 58, 318-328. doi: 10.2337/db08-0799

Mayer, E. A., Padua, D., and Tillisch, K. (2014a). Altered brain-gut axis in autism: comorbidity or causative mechanisms? Bioessays 36, 933-939. doi: 10.1002/bies.201400075

Mayer, E. A., Savidge, T., and Shulman, R. J. (2014b). Brain-gut microbiome interactions and functional bowel disorders. Gastroenterology 146, 1500-1512. doi: $10.1053 /$ j.gastro.2014.02.037

Morris, A. (2017). Diabetes: pancreatic GLP1 is involved in glucose regulation. Nat. Rev. Endocrinol. 13:252. doi: 10.1038/nrendo.2017.35

Movahed, A., Nabipour, I., Lieben Louis, X., Thandapilly, S. J., Yu, L., Kalantarhormozi, M., et al. (2013). Antihyperglycemic effects of short term resveratrol supplementation in type 2 diabetic patients. Evid. Based Complement. Alternat. Med. 2013:851267. doi: 10.1155/2013/851267

Mulvihill, E. E. (2018). Regulation of intestinal lipid and lipoprotein metabolism by the proglucagon-derived peptides glucagon like peptide 1 and glucagon like peptide 2. Curr. Opin. Lipidol. 29, 95-103. doi: 10.1097/MOL.0000000000000495

Nabavi, S. M., Daglia, M., Braidy, N., and Nabavi, S. F. (2017). Natural products, micronutrients, and nutraceuticals for the treatment of depression: a short review. Nutr. Neurosci. 20, 180-194. doi: 10.1080/1028415X.2015.1103461

Nonogaki, K., and Kaji, T. (2018). Liraglutide, a GLP-1 receptor agonist, which decreases hypothalamic 5-HT2A receptor expression, reduces appetite and body weight independently of serotonin synthesis in mice. J. Diabetes Res. 2018:6482958. doi: 10.1155/2018/6482958

Novelle, M. G., Wahl, D., Dieguez, C., Bernier, M., and De Cabo, R. (2015). Resveratrol supplementation: where are we now and where should we go? Ageing Res. Rev. 21, 1-15. doi: 10.1016/j.arr.2015.01.002

O'mahony, S., Dinan, T. G., Keeling, P. W., and Chua, A. S. (2006). Central serotonergic and noradrenergic receptors in functional dyspepsia. World J. Gastroenterol. 12, 2681-2687. doi: 10.3748/wjg.v12.117.2681

Parker, A., Fonseca, S., and Carding, S. R. (2020). Gut microbes and metabolites as modulators of blood-brain barrier integrity and brain health. Gut Microbes 11, 135-157. doi: 10.1080/19490976.2019.1638722

Parker, C. G., Dailey, M. J., Phillips, H., and Davis, E. A. (2020). Central sensorymotor crosstalk in the neural gut-brain axis. Auton. Neurosci. 225:102656. doi: 10.1016/j.autneu.2020.102656

Peng, Y., Zhao, S., Wu, Y., Cao, H., Xu, Y., Liu, X., et al. (2018). Identification of natural products as novel ligands for the human 5-HT2C receptor. Biophys. Rep. 4, 50-61. doi: 10.1007/s41048-018-0047-1

Perry, T., Lahiri, D. K., Chen, D., Zhou, J., Shaw, K. T., Egan, J. M., et al. (2002). A novel neurotrophic property of glucagon-like peptide 1: a promoter of nerve growth factor-mediated differentiation in PC12 cells. J. Pharmacol. Exp. Ther. 300, 958-966. doi: 10.1124/jpet.300.3.958

Prasad, S., Ponimaskin, E., and Zeug, A. (2019). Serotonin receptor oligomerization regulates cAMP-based signaling. J. Cell Sci. 132:jcs230334. doi: $10.1242 /$ jcs. 230334

Qiao, Y., Sun, J., Xia, S., Tang, X., Shi, Y., and Le, G. (2014). Effects of resveratrol on gut microbiota and fat storage in a mouse model with high-fat-induced obesity. Food Funct. 5, 1241-1249. doi: 10.1039/c3fo60630a

Ramadori, G., Gautron, L., Fujikawa, T., Vianna, C. R., Elmquist, J. K., and Coppari, R. (2009). Central administration of resveratrol improves dietinduced diabetes. Endocrinology 150, 5326-5333. doi: 10.1210/en.2009-0528

Rehman, K., Saeed, K., Munawar, S. M., and Akash, M. S. H. (2018). Resveratrol regulates hyperglycemia-induced modulations in experimental diabetic animal model. Biomed. Pharmacother. 102, 140-146. doi: 10.1016/j.biopha.2018. 03.050

Reierson, G. W., Guo, S., Mastronardi, C., Licinio, J., and Wong, M. L. (2011). cGMP signaling, phosphodiesterases and major depressive disorder. Curr. Neuropharmacol. 9, 715-727. doi: 10.2174/157015911798376271
Ren, X., Chen, L., Xie, J., Zhang, Z., Dong, G., Liang, J., et al. (2017). Resveratrol ameliorates mitochondrial elongation via Drp1/Parkin/PINK1 signaling in senescent-like cardiomyocytes. Oxid. Med. Cell. Longev. 2017:4175353. doi: $10.1155 / 2017 / 4175353$

Rhee, S. H., Pothoulakis, C., and Mayer, E. A. (2009). Principles and clinical implications of the brain-gut-enteric microbiota axis. Nat. Rev. Gastroenterol. Hepatol. 6, 306-314. doi: 10.1038/nrgastro.2009.35

Ripken, D., Van Der Wielen, N., Wortelboer, H. M., Meijerink, J., Witkamp, R. F., and Hendriks, H. F. (2016). Nutrient-induced glucagon like peptide1 release is modulated by serotonin. J. Nutr. Biochem. 32, 142-150. doi: 10.1016/j.jnutbio.2016.03.006

Rivera, L., Moron, R., Zarzuelo, A., and Galisteo, M. (2009). Long-term resveratrol administration reduces metabolic disturbances and lowers blood pressure in obese zucker rats. Biochem. Pharmacol. 77, 1053-1063. doi: 10.1016/j.bcp.2008.11.027

Rom, S., Zuluaga-Ramirez, V., Gajghate, S., Seliga, A., Winfield, M., Heldt, N. A., et al. (2019). Hyperglycemia-driven neuroinflammation compromises BBB leading to memory loss in both diabetes mellitus (DM) type 1 and type 2 mouse models. Mol. Neurobiol. 56, 1883-1896. doi: 10.1007/s12035-018-1195-5

Rotches-Ribalta, M., Andres-Lacueva, C., Estruch, R., Escribano, E., and UrpiSarda, M. (2012). Pharmacokinetics of resveratrol metabolic profile in healthy humans after moderate consumption of red wine and grape extract tablets. Pharmacol. Res. 66, 375-382. doi: 10.1016/j.phrs.2012.08.001

Sadruddin, S., and Arora, R. (2009). Resveratrol: biologic and therapeutic implications. J. Cardiometab. Syndr. 4, 102-106 doi: $10.1111 / j .1559-4572.2008 .00039 . x$

Salehi, M., and Purnell, J. Q. (2019). The role of glucagon-like peptide1 in energy homeostasis. Metab. Syndr. Relat. Disord. 17, 183-191. doi: $10.1089 /$ met.2018.0088

Samson, S. L., and Bajaj, M. (2013). Direct actions of GLP-1 analogues on AMPactivated protein kinase activity are distinct from cyclic AMP accumulation. J. Hepatol. 58, 634-635. doi: 10.1016/j.jhep.2012.10.032

Sarkar, S., Fekete, C., Legradi, G., and Lechan, R. M. (2003). Glucagon like peptide1 (7-36) amide (GLP-1) nerve terminals densely innervate corticotropinreleasing hormone neurons in the hypothalamic paraventricular nucleus. Brain Res. 985, 163-168. doi: 10.1016/S0006-8993(03)03117-2

Shah, A., Xia, L., Goldberg, H., Lee, K. W., Quaggin, S. E., and Fantus, I. G. (2013). Thioredoxin-interacting protein mediates high glucose-induced reactive oxygen species generation by mitochondria and the NADPH oxidase, Nox4, in mesangial cells. J. Biol. Chem. 288, 6835-6848. doi: 10.1074/jbc.M112.419101

Shang, J., Chen, L. L., Xiao, F. X., Sun, H., Ding, H. C., and Xiao, H. (2008). Resveratrol improves non-alcoholic fatty liver disease by activating AMP-activated protein kinase. Acta Pharmacol. Sin. 29, 698-706. doi: 10.1111/j.1745-7254.2008.00807.x

Sharon, G., Cruz, N. J., Kang, D. W., Gandal, M. J., Wang, B., Kim, Y. M., et al. (2019). Human gut microbiota from autism spectrum disorder promote behavioral symptoms in mice. Cell 177, 1600-1618.e1617. doi: 10.1016/j.cell.2019.05.004

Shi, J. X., and Huang, Q. (2018). Glucagonlike peptide1 protects mouse podocytes against high glucoseinduced apoptosis, and suppresses reactive oxygen species production and proinflammatory cytokine secretion, through sirtuin 1 activation in vitro. Mol. Med. Rep. 18, 1789-1797. doi: 10.3892/mmr. 2018.9085

Simren, M., Tornblom, H., Palsson, O. S., Van Oudenhove, L., Whitehead, W. E., and Tack, J. (2019). Cumulative effects of psychologic distress, visceral hypersensitivity, and abnormal transit on patient-reported outcomes in irritable bowel syndrome. Gastroenterology 157, 391-402.e392. doi: 10.1053/j.gastro.2019.04.019

Simren, M., Tornblom, H., Palsson, O. S., Van Tilburg, M. A. L., Van Oudenhove, L., Tack, J., et al. (2018). Visceral hypersensitivity is associated with GI symptom severity in functional GI disorders: consistent findings from five different patient cohorts. Gut 67, 255-262. doi: 10.1136/gutjnl-2016-312361

Singh, C. K., Liu, X., and Ahmad, N. (2015). Resveratrol, in its natural combination in whole grape, for health promotion and disease management. Ann. N. Y. Acad. Sci. 1348, 150-160. doi: 10.1111/nyas.12798

Smith, D. L. Jr., Li, C., Matecic, M., Maqani, N., Bryk, M., and Smith, J. S. (2009). Calorie restriction effects on silencing and recombination at the yeast rDNA. Aging Cell 8, 633-642. doi: 10.1111/j.1474-9726.2009.00516.x 
Spohn, S. N., Bianco, F., Scott, R. B., Keenan, C. M., Linton, A. A., O'neill, C. H., et al. (2016). Protective actions of epithelial 5-hydroxytryptamine 4 receptors in normal and inflamed colon. Gastroenterology 151, 933-944.e933. doi: 10.1053/j.gastro.2016.07.032

Sun, L., Ma, L., Zhang, H., Cao, Y., Wang, C., Hou, N., et al. (2019). Fto deficiency reduces anxiety- and depression-like behaviors in mice via alterations in gut microbiota. Theranostics 9, 721-733. doi: 10.7150/thno.31562

Tauchi, M., Zhang, R., D’alessio, D. A., Stern, J. E., and Herman, J. P. (2008). Distribution of glucagon-like peptide-1 immunoreactivity in the hypothalamic paraventricular and supraoptic nuclei. J. Chem. Neuroanat. 36, 144-149. doi: 10.1016/j.jchemneu.2008.07.009

Thazhath, S. S., Wu, T., Bound, M. J., Checklin, H. L., Standfield, S., Jones, K. L., et al. (2016). Administration of resveratrol for $5 \mathrm{wk}$ has no effect on glucagon-like peptide 1 secretion, gastric emptying, or glycemic control in type 2 diabetes: a randomized controlled trial. Am. J. Clin. Nutr. 103, 66-70. doi: 10.3945/ajcn.115.117440

Timmers, S., Konings, E., Bilet, L., Houtkooper, R. H., Van De Weijer, T., Goossens, G. H., et al. (2011). Calorie restriction-like effects of 30 days of resveratrol supplementation on energy metabolism and metabolic profile in obese humans. Cell Metab. 14, 612-622. doi: 10.1016/j.cmet.2011.10.002

Vahl, T. P., Tauchi, M., Durler, T. S., Elfers, E. E., Fernandes, T. M., Bitner, R. D., et al. (2007). Glucagon-like peptide-1 (GLP-1) receptors expressed on nerve terminals in the portal vein mediate the effects of endogenous GLP-1 on glucose tolerance in rats. Endocrinology 148, 4965-4973. doi: 10.1210/en.2006-0153

Vassilopoulos, A., Fritz, K. S., Petersen, D. R., and Gius, D. (2011). The human sirtuin family: evolutionary divergences and functions. Hum. Genomics 5, 485-496. doi: 10.1186/1479-7364-5-5-485

Vilsboll, T., and Holst, J. J. (2004). Incretins, insulin secretion and Type 2 diabetes mellitus. Diabetologia 47, 357-366. doi: 10.1007/s00125-004-1342-6

Walle, T. (2011). Bioavailability of resveratrol. Ann. N. Y. Acad. Sci. 1215, 9-15. doi: 10.1111/j.1749-6632.2010.05842.x

Wang, L., Xu, M., Liu, C., Wang, J., Xi, H., Wu, B., et al. (2013). Resveratrols in grape berry skins and leaves in vitis germplasm. PLoS ONE 8:e61642. doi: 10.1371/journal.pone.0061642

Wang, Y., Chen, S., Xu, Z., Chen, S., Yao, W., and Gao, X. (2018). GLP-1 receptor agonists downregulate aberrant GnT-III expression in Alzheimer's disease models through the Akt/GSK-3beta/beta-catenin signaling. Neuropharmacology 131, 190-199. doi: 10.1016/j.neuropharm.2017.11.048

Wu, B., Basu, S., Meng, S., Wang, X., and Hu, M. (2011). Regioselective sulfation and glucuronidation of phenolics: insights into the structural basis. Curr. Drug Metab. 12, 900-916. doi: 10.2174/138920011797470100

Xu, F., Li, Z., Zheng, X., Liu, H., Liang, H., Xu, H., et al. (2014). SIRT1 mediates the effect of GLP-1 receptor agonist exenatide on ameliorating hepatic steatosis. Diabetes 63, 3637-3646. doi: 10.2337/db14-0263

Xu, L., Botchway, B. O. A., Zhang, S., Zhou, J., and Liu, X. (2018). Inhibition of NFkappaB signaling pathway by resveratrol improves spinal cord injury. Front. Neurosci. 12:690. doi: 10.3389/fnins.2018.00690

Xu, Y., Cui, S. Y., Ma, Q., Shi, J., Yu, Y., Li, J. X., et al. (2018). transresveratrol ameliorates stress-induced irritable bowel syndrome-like behaviors by regulation of brain-gut axis. Front. Pharmacol. 9:631. doi: 10.3389/fphar.2018.00631

Xu, Y., Wang, Z., You, W., Zhang, X., Li, S., Barish, P. A., et al. (2010). Antidepressant-like effect of trans-resveratrol: involvement of serotonin and noradrenaline system. Eur. Neuropsychopharmacol. 20, 405-413. doi: 10.1016/j.euroneuro.2010.02.013

Yano, J. M., Yu, K., Donaldson, G. P., Shastri, G. G., Ann, P., Ma, L., et al. (2015). Indigenous bacteria from the gut microbiota regulate host serotonin biosynthesis. Cell 161, 264-276. doi: 10.1016/j.cell.2015.02.047

Yarandi, S. S., Peterson, D. A., Treisman, G. J., Moran, T. H., and Pasricha, P. J. (2016). Modulatory effects of gut microbiota on the central nervous system: how gut could play a role in neuropsychiatric health and diseases. J. Neurogastroenterol. Motil. 22, 201-212. doi: 10.5056/jnm15146

Yohn, C. N., Gergues, M. M., and Samuels, B. A. (2017). The role of 5-HT receptors in depression. Mol. Brain 10:28. doi: 10.1186/s13041-017-0306-y

Yu, Y., Wang, R., Chen, C., Du, X., Ruan, L., Sun, J., et al. (2013). Antidepressant-like effect of trans-resveratrol in chronic stress model: behavioral and neurochemical evidences. J. Psychiatr. Res. 47, 315-322. doi: 10.1016/j.jpsychires.2012.10.018

Yu, Y. C., Li, J., Zhang, M., Pan, J. C., Yu, Y., Zhang, J. B., et al. (2019). Resveratrol improves brain-gut axis by regulation of 5-HT-dependent signaling in the rat model of irritable bowel syndrome. Front. Cell. Neurosci. 13:30. doi: 10.3389/fncel.2019.00030

Zhao, H., Zhang, Y., Shu, L., Song, G., and Ma, H. (2019). Resveratrol reduces liver endoplasmic reticulum stress and improves insulin sensitivity in vivo and in vitro. Drug Des. Devel. Ther. 13, 1473-1485. doi: 10.2147/DDDT.S203833

Zhou, R., Yi, L., Ye, X., Zeng, X., Liu, K., Qin, Y., et al. (2018). Resveratrol ameliorates lipid droplet accumulation in liver through a SIRT1/ ATF6-dependent mechanism. Cell. Physiol. Biochem. 51, 2397-2420. doi: $10.1159 / 000495898$

Zhuang, Y., Wu, H., Wang, X., He, J., He, S., and Yin, Y. (2019). Resveratrol attenuates oxidative stress-induced intestinal barrier injury through PI3K/Aktmediated Nrf2 signaling pathway. Oxid. Med. Cell. Longev. 2019:7591840. doi: 10.1155/2019/7591840

Zou, T., Chen, D., Yang, Q., Wang, B., Zhu, M. J., Nathanielsz, P. W., et al. (2017) Resveratrol supplementation of high-fat diet-fed pregnant mice promotes brown and beige adipocyte development and prevents obesity in male offspring. J. Physiol. 595, 1547-1562. doi: 10.1113/JP273478

Conflict of Interest: The authors declare that the research was conducted in the absence of any commercial or financial relationships that could be construed as a potential conflict of interest.

Copyright (c) 2020 Chung, Jeong and Song. This is an open-access article distributed under the terms of the Creative Commons Attribution License (CC BY). The use, distribution or reproduction in other forums is permitted, provided the original author(s) and the copyright owner(s) are credited and that the original publication in this journal is cited, in accordance with accepted academic practice. No use, distribution or reproduction is permitted which does not comply with these terms. 